\title{
VISION SYSTEM FOR SPRAYING MACHINE ADAPTIVE CONTROL
}

\author{
Matache Mihai, Persu Catalin, Nitu Mihaela, Gheorghe Gabriel \\ National Institute of Research-Development for Machines and Installations \\ Designed to Agriculture and Food Industry, Romania \\ gabimatache@yahoo.com
}

\begin{abstract}
A sustainable approach for nowadays precision agriculture implies also the reduction of phytosanitary substances used for treatment of field crops. Usually, a field crop spraying machine uses a previously set quantity of herbicides without taking into consideration the actual amount of weeds within the field. Without having a clear picture of the crop degree of infestation with weeds, this approach leads sometimes to overspraying and to crop contamination because of the chemical substances remanence in time. The paper presents a modern approach to this problem by fitting the spraying machine with a vision control system used for analyzing in real time the field degree of infestation with weeds and deciding the right amount of herbicides to use based on that. Thus, the spraying machine is able to change in real time its working pressure on different nozzle segments, making a high herbicides economy as well as becoming more environmental friendly. Within the paper the vision algorithm will be presented used for weed area identification based on real time pictures of the field and the means it is used for the spraying machine adaptive control. This algorithm was implemented using NI 1774C color smart cameras, essential components of the vision control system of a 12 meters wide field crop spraying machine ported by an $80 \mathrm{HP}$ tractor. The control system consisted also of a PLC, which processed information received from smart cameras and pressure sensors and commanded the electronic valves mounted on the machine hydraulic distributor, using a negative feedback loop. The machine had 24 nozzles, disposed over 3 segments of equal length. Further on, the experimental results obtained in real conditions will be presented and compared with performances obtained by classical weed treatment in the field.
\end{abstract}

Keywords: vision system, spraying machine, smart camera.

\section{Introduction}

Weeds are unwanted plants that grow in the most variated ecological conditions, do not have an economical utility and are usually harmful, impeding human economic activities. Weeds grow together with the species cultivated, competing with them and decreasing their yields. For this purpose, in order to destroy weeds, direct methods of destruction are used, the most used one being the use of herbicide substances. For an optimal use of herbicides, it is necessary to know the structure of crops and their rotations; to know the main types of weeds, especially of those that are problematic, accompanying each crop and those that are spread in the respective area; to establish the herbicides or herbicide mixes to be used, the dosages, times and methods of applying them depending on the weeds present [1]. Nowadays, in order to obtain healthy products with an impact on the environment as small as possible, sustainable methods to reduce the quantity of herbicides are imposed, thus the doses of the herbicides applied need to be correlated with the degree of weed infestation.

It is necessary for the farmer to know well each herbicide, the remanence duration, its influencing manner and to avoid the accumulation of large quantities that can unfavorably influence the biological activity in the soil.

Residual toxicity in the soil can be decreased (or avoided) by applying herbicides as follows:

1. in minimum, but effective dose;

2. as early as possible in the warm season of the vegetation period;

3. in strips, this way reducing the quantity of herbicide per hectare;

4. in mixtures (usually two herbicides) to increase the specter of fighting weeds with two smaller doses of herbicide.

More exact decisions on the inputs in the system (agro-phyto-technical measures and especially herbicide application) after sowing the crops can only be taken knowing the local conditions (soil, climate, diseases and weed infestation degree etc.). One image analysis technique was used for detection of diseases in field crops and orchards proving that vision systems could be a serious helping instrument for farmers [2;3]. Further on, [4] proposed a method for identifying weeds by taking pictures and analyzing them. The photos were taken at certain intervals and simultaneously samples of weeds were collected, for which the size (height, width) and leaf measurements (biomass size, surface) were determined. Also [5] took into consideration the possibility to identify crop plants and weeds 
based on images taken in the field. Worldwide solutions were tested for automating the process of spraying crops, using image recognition algorithms. In [6] the authors used a vision-based approach in order to identify and destroy a certain type of weed in the field. They segmented the crop images in cells, which after a specific identifying algorithm were labeled with the decision to be sprayed or not. Further on, a representative example is the one achieved by [7] in 2009. They automated a classic spraying machine having the working width of $10 \mathrm{~m}$, with 5 independent boom segments, $2 \mathrm{~m}$ each. The researchers endowed the equipment with a vision system for identifying the rows and the weeds in the crop in real time. The information from the vision system was used for controlling the working parameters of the spraying machine. [8] also used vision systems for controlling an equipment for destroying weeds in cereal crops.

The paper presents a modern approach to the problem of sustainable use of herbicides, using smart cameras for analyzing in real time the culture's degree of infestation with weeds and deciding the right amount of herbicide to use based on that. Within the paper the vision algorithm implemented in the smart camera memory will be presented, used for weed area identification based on real time pictures of the crop and the way the information is used for spraying machine adaptive control.

\section{Materials and methods}

For experiments a spraying machine was chosen with the working width of $12 \mathrm{~m}$, formed by 3 independent boom segments, $4 \mathrm{~m}$ each.

The spraying machine was endowed with a smart system for $t$ active control of work for performing phytosanitary treatments in field crops, composed of the following elements.

Image recognition system, destined for quantifying the crop degree of weed infestation, composed of two smart cameras for acquiring and processing images (in color) each fitted on a mechanical stabilizer and a speed sensor fitted on the tractor wheel to correlate data acquisition with the movement speed. Through the means of this system the vision algorithm was implemented used for weed area identification based on real pictures of the field. Each camera monitored a working width of approximately $6 \mathrm{~m}$.

Technical system destined for active control of the working parameters of the spraying machine, formed of a central control unit with graphical user interface and equipment for controlling the spraying process (pressure and flow rate sensors, electrically controlled hydraulic distributor).

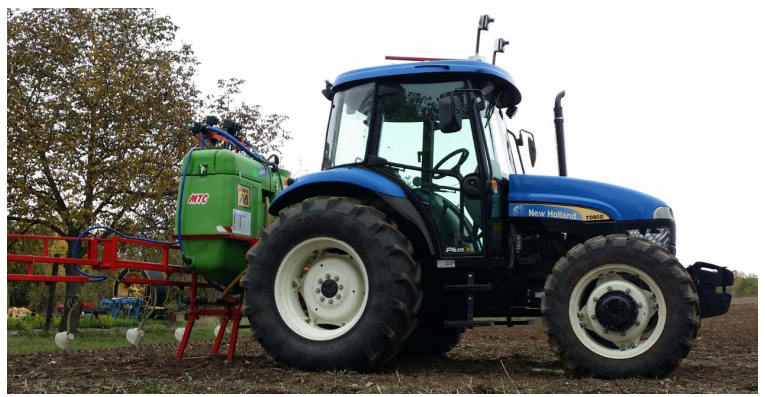

\section{Fig. 1. Experimental model of the smart system for active control of work for performing phytosanitary treatments}

The operation manner of the equipment implies capturing images of the crop positioned in front of the spraying machines, by the smart cameras positioned on the tractor roof, synchronized with its movement speed. The cameras analyze the images using the recognition algorithm and will transmit towards the control unit the crop degree of weed infestation, on interest areas, identical in width with the width of the spraying boom segments. The control unit calculates the norm of phytosanitary substance depending on the degree of weed infestation and commands, through a specific command algorithm, the valves with the motor that feed each boom segment. The command algorithm is based on switching algorithm in paces of $50 \%$, governed by fuzzy rules. This can be largely explained that the flow of each segment can either be $100 \%, 50 \%$ or $0 \%$ from the nominal set flow. Therefore, different quantities will be applied on each boom segment, correlated with the percentage of weeds in the areas covered by them. 
The graphic user interface allows selecting the reference norm of phytosanitary substances for the treated crop and to visualize the working parameters (pressure, flow rate, speed, etc.).

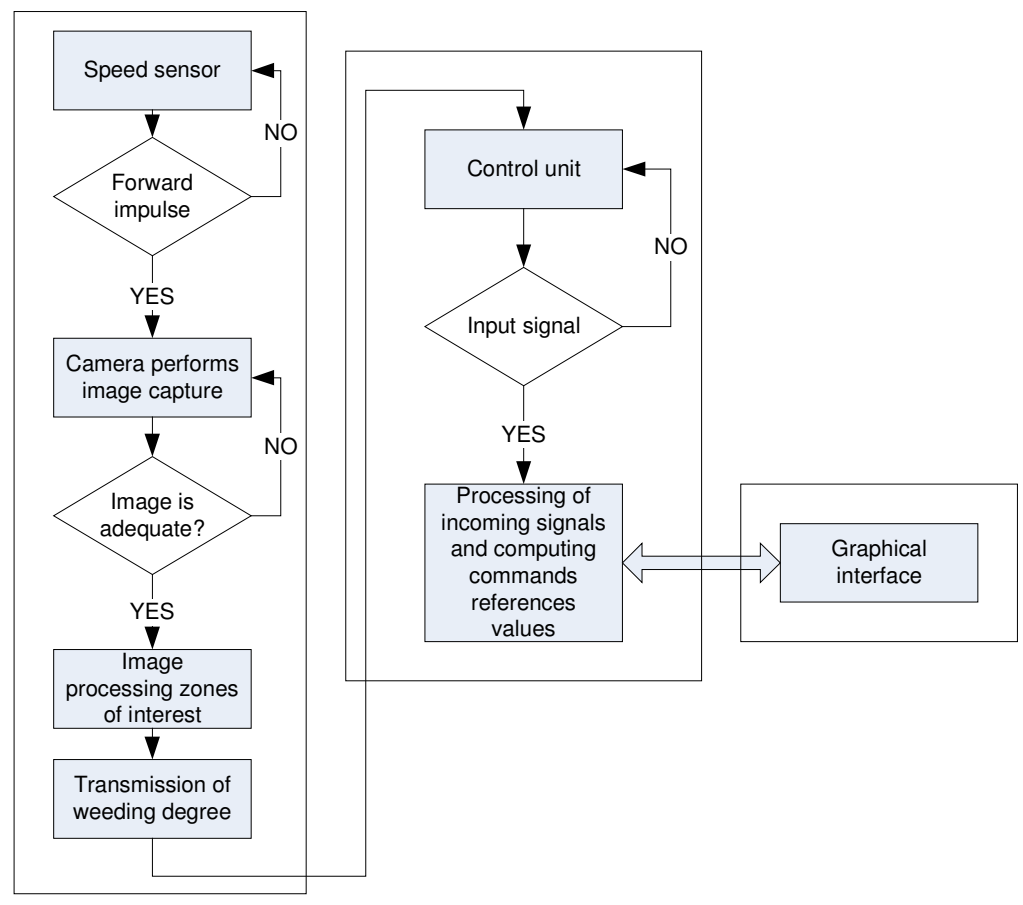

Fig. 2. Logic diagram for equipment control

The smart cameras used were of the NI 1774C type, in color, with a resolution of 1280x960 at a maximum frame rate of $17 \mathrm{fps}$.

The vision algorithm for weed area identification was implemented using the NI Vision Builder programing media, compatible with NI 1774C type cameras. They have a rewritable internal memory that can store the software program steps and have an integrated controller that can perform image processing operations. Characteristic for this type of cameras is the fact that they are compact, in the same frame having incorporated the following components: lens with fixed focal distance lens, camera with CCD image sensor and image processing system.

The vision algorithm for weed area identification respected the following principal stages.

- Real time image sampling, taken directly from the field and segmenting them into interest regions. This segmentation is performed for the purpose of attributing for each investigated area the corresponding boom segment that is going to apply the phytosanitary treatment. Image sampling is done by hardware trigger, commanded at each 5 meters covered by the movement speed sensor fitted on the tractor wheel. These $5 \mathrm{~m}$ correspond to maximum image depth, which can be achieved by the cameras lens at the 45 degrees tilting angle that they were set. This way the entire field can be continuously swept so that the real degree of weed infestation will be assessed.

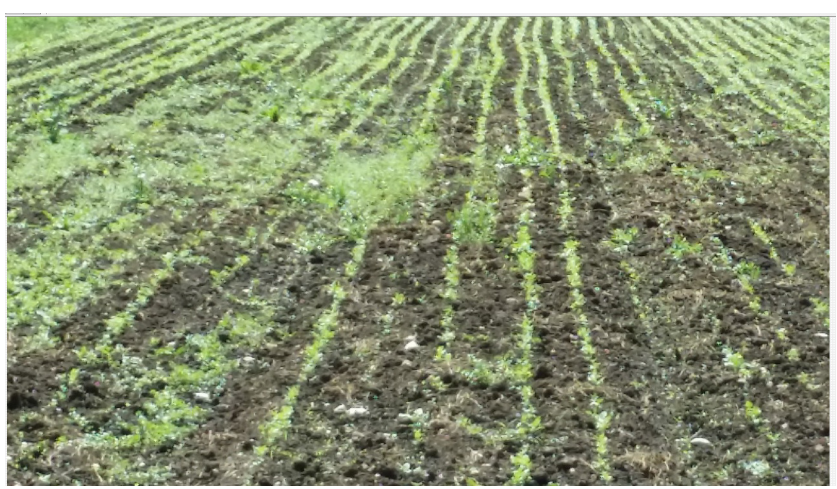

Fig. 3. Image sampling 
- Identifying crop rows for each interest area analyzed. This operation is made by means of vision technique, like extracting the RGB green plane from the picture and then pixel counting over a set threshold in order to assess the percent that the crop plants cover on the investigated field.

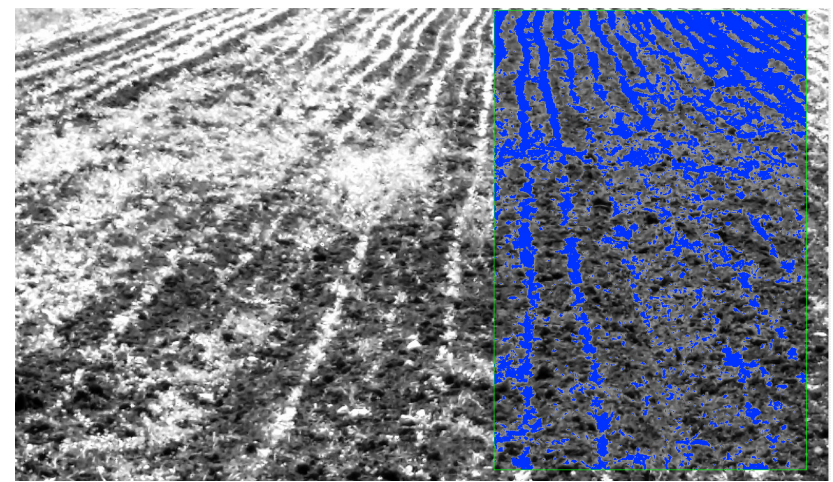

Fig. 4. Identifying crop rows - blue coloured

- Identifying the space between crop rows for each interest area analyzed; this operation is done in order to assess the amount of soil, which is not covered with plants or weeds.

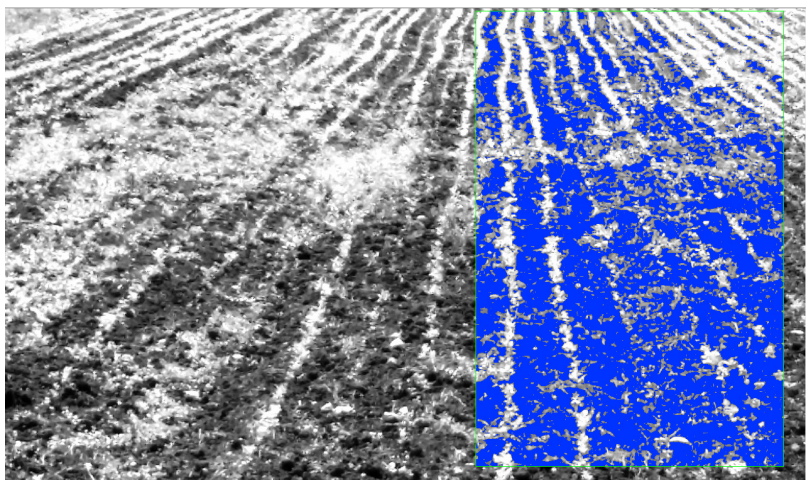

Fig. 5. Identifying the space between crop rows - blue coloured

- Determining the percentage degree of weed infestation, by conducting an analysis on the color difference between the surface covered by weeds, the soil and crop rows. Depending on the degree of weed infestation of surfaces analyzed, the command is transmitted to the control unit so that optimum phytosanitary substance application is achieved.

Following, we performed a comparative study regarding the spraying machine comportment, whether it is fitted with the vision system or with the classical control system. In order to achieve this, we have chosen three working speeds with one fixed spraying norm and different nozzle sizes and we performed spraying operations with water on the same control field for each situation. We measured the quantity of water used in each case.

In Table 1 the experimental testing conditions taken into consideration are presented.

Table 1

Testing conditions

\begin{tabular}{|c|c|c|c|c|}
\hline Crt. no & Nozzle type & $\begin{array}{c}\text { Working speed, } \\
\mathbf{k m} \cdot \mathbf{h}^{-\mathbf{1}}\end{array}$ & $\begin{array}{c}\text { Working } \\
\text { pressure, bar }\end{array}$ & $\begin{array}{c}\text { Imposed Norm, } \\
\mathbf{I}^{-\mathbf{h a}^{-1}}\end{array}$ \\
\hline 1 & ISO 11004 & 8 & 3 & 240 \\
\hline 2 & ISO 11005 & 10 & 3 & 240 \\
\hline 3 & ISO 11006 & 12 & 3 & 240 \\
\hline
\end{tabular}

The testing was performed on a 12 meter wide field with a total length of 200 meters, totalizing 0.24 ha surface. The field was cultivated with maize and was left intentionally untreated so that the weeds could develop. The field degree of infestation with weeds was previously assessed through statistical sampling procedures to a level of $40 \%$ coverage degree. The assessment of the used 
quantity of liquid was done after each pass, for both situations: the spraying machine fitted with the vision system and without.

During the tests with the vision system we obtained a covering degree evaluation, which further led to switching control of the spraying machine distributor. The entire field was segmented into 40 areas with a length of $5 \mathrm{~m}$ on the entire length of the field. Then each area was evaluated by the two smart cameras on the 3 regions of interest according to the 3 boom segments. Figure 6 presents the evolution of the measured coverage degree (a mean of the values measured by the two cameras), on the entire length of the experimental field.

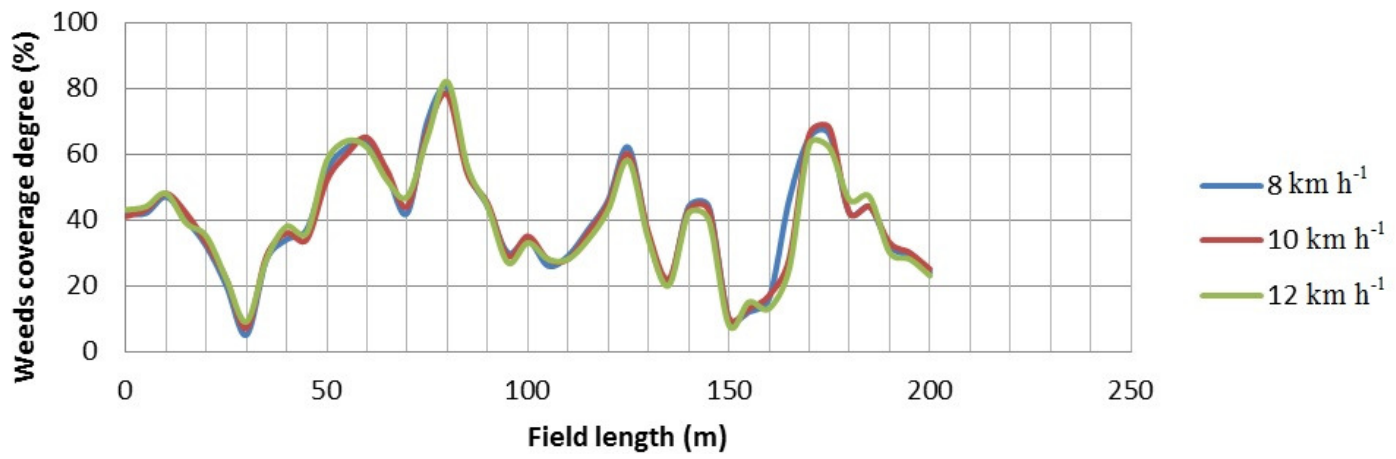

Fig. 6. Weed coverage degree evaluated for entire lenght of the experimental field

In Table 2 the mean results obtained for the entire control field in terms of weed coverage are presented.

Table 2

Results obtained for the control field

\begin{tabular}{|c|c|c|c|}
\hline Crt. no & $\begin{array}{c}\text { Nozzle } \\
\text { type }\end{array}$ & $\begin{array}{c}\text { Working } \\
\text { speed, } \\
\mathbf{k m}^{-1} \mathbf{h}^{-1}\end{array}$ & $\begin{array}{c}\text { Covering } \\
\text { degree with } \\
\text { weeds, \% }\end{array}$ \\
\hline 1 & ISO 11004 & 8 & 39.8 \\
\hline 2 & ISO 11005 & 10 & 37.9 \\
\hline 3 & ISO 11006 & 12 & 38.2 \\
\hline
\end{tabular}

By comparing the data obtained for the coverage degree mean value from Table 3 we see that they are strongly correlated. Looking at the diagrams from Figure 6 we can notice a slight difference between the measured values for different working speeds on the same tracks. These differences are explained by several perturbative factors, which could not be taken into consideration, like the slip of the tractor wheels and the shades due to the changing clouds in the sky. However, the overall performance of the vision system showed good results with standard deviation between 1 and $5 \%$ per region of interest.

In Table 3 the results are presented obtained during the experiments performed in the field, comparing the spraying machine with classic control with the same machine endowed with the vision system control. In order to obtain valid results, the tests were performed on the same field and over the same tracks using GPS guidance.

Table 3

Results in the field comparing the classical machine with the one with the vision system

\begin{tabular}{|c|c|c|c|c|c|c|}
\hline $\begin{array}{c}\text { Crt. } \\
\text { no }\end{array}$ & $\begin{array}{c}\text { Nozzle } \\
\text { type }\end{array}$ & $\begin{array}{c}\text { Working } \\
\text { speed, } \mathbf{~ k m \cdot h} \mathbf{h}^{-\mathbf{1}}\end{array}$ & $\begin{array}{c}\text { Imposed } \\
\text { quantity of } \\
\text { liquid, I }\end{array}$ & $\begin{array}{c}\text { Spraying } \\
\text { machine } \\
\text { fitted with } \\
\text { classical } \\
\text { control, } \mathbf{~}\end{array}$ & $\begin{array}{c}\text { Spraying } \\
\text { machine } \\
\text { fitted with } \\
\text { vision system, } \\
\mathbf{l}\end{array}$ & $\begin{array}{c}\text { Difference, } \\
\mathbf{\%}\end{array}$ \\
\hline 1 & ISO 11004 & 8 & 57.6 & 58.8 & 50.4 & 14.29 \\
\hline 2 & ISO 11005 & 10 & 57.6 & 58.1 & 50.6 & 12.91 \\
\hline 3 & ISO 11006 & 12 & 57.6 & 57.4 & 50.3 & 12.37 \\
\hline
\end{tabular}




\section{Conclusions}

The use of the vision system has led to resembling result regarding the weed infestation degree of a test field, no matter the testing conditions. This has further led to reducing the amount of liquids used in the spraying process with around $13 \%$ compared with the classical treatment. The results are strongly influenced by the switching control algorithm and the field testing conditions, from which mainly the initial covering degree with weeds. However, the obtained results could firstly mean a reduction of the costs with phytosanitary substances by approximately $13 \%$. Also we have to think of the positive implications on the environment protection and food safety that this approach could have.

The vision system could be adapted to most of the spraying machines, which are on the market nowadays without major functional modifications. In could also be adapted to bigger working widths simply by increasing the number of smart cameras, which are to investigate the total working width of the spraying machine. It has potential especially for crops, which usually have high weed amount infested areas mixed with low amount of weeds areas.

\section{Acknowledgement}

This work was funded by the Executive Agency for Higher Education, Research, Development and Innovation Funding, within the project entitled "PN 162401 05: Intelligent system for active control of phytosanitary treatments realization works in field crops, in function of their degree with weeds infestation", ctr. 8N/09.03.2016 / Ad. no.1/2017.

\section{References}

1. Berca Mihai - Integrated weed management, CERES Publishing House, 2004, ISBN 9734006525;

2. Karl-Heinz Dammer, Bernd Möller, Bernd Rodemann, Dirk Heppner - Detection of head blight (Fusarium ssp.) in winter wheat by color and multispectral image analyses, Crop Protection 30 (2011), pp. 420-428.

3. Alireza Pourreza, Won Suk Lee, Reza Ehsani, John K. Schueller, Eran Raveh - An optimum method for real-time in-field detection of Huanglongbing disease using a vision sensor, Computers and Electronics in Agriculture 110 (2015), pp. 221-232;

4. Martin-Chefson L., Assemat L., Boissard P. - A two dimensional method for recognizing weeds from multiband image processing, 2-nd European Conference on precision Agriculture 1999, pp. 473-483.

5. Faisal Ahmed, Hawlader Abdullah Al-Mamun, A.S.M. Hossain Bari, Emam Hossain, Paul Kwan - Classification of crops and weeds from digital images: A support vector machine approach, Crop Protection 40 (2012), pp. 98-104.

6. Alberto Tellaeche, Xavier P. BurgosArtizzu, Gonzalo Pajares, Angela Ribeiro, Ce'sar Ferna'ndez-Quintanilla - A new vision-based approach to differential spraying in precision agriculture, Computers And Electronics in Agriculture 60 (2008), pp.144-155.

7. Xavier P. Burgos Artizzua, Angela Ribeiroa, Maria Guijarrob, Gonzalo Pajaresb - Real-time image processing for crop/weed discrimination in maize fields, Computers and Electronics in Agriculture 75 (2011), pp. 337-346.

8. T.W. Berge, S. Goldberg, K. Kaspersen, J. Netland - Towards machine vision based site-specific weed management in cereals, Computers and Electronics in Agriculture 81 (2012), pp. 79-86. 